\title{
Why do monetary policies matter? An experimental study of saving and inflation in an overlapping generations model*
}

\author{
Michele Bernasconi \\ Dipartimento di Scienze Economiche e Sociali — Università di Napoli ${ }^{\dagger}$ \\ Oliver Kirchkamp \\ SFB 504 - Universität Mannheim *
}

November 1999

\begin{abstract}
We study experiments of an overlapping generations model where inflation is determined by the monetary policy and by the amount of average saving within each period.

We use a new experimental setup that allows us to observe more details of the process of expectation forming and separate this process from the actual saving process.

In contrast to experimental findings by Lim, Prescott, Sunder; Marimon, Spear, Sunder; and Marimon, Sunder we find that (1) agents do not form first-order adaptive expectations; (2) subjects 'over-save' for precautionary reasons; as a result (3) the so-called Friedman conjecture holds, i.e. monetary policies which are equivalent in static equilibrium exhibit different levels and different volatility of inflation in the experiment. This may generate important policy trade-offs between monetary regimes. We discuss our findings and relate them to current research on adaptive learning and the role it may have in ranking alternative monetary policies.
\end{abstract}

Keywords: OLG-model, expectations, inflation, stability, monetary policy, experiments.

JEL-Classification: C92,E21,E31,E52

\footnotetext{
${ }^{*}$ A demo page of the experiment can be found at: http://www.sfb504.uni-mannheim.de/ kirchkamp /noi.html.

We thank the Italian CNR and MURST and the German DFG (SFB 504) for funding the project. The project started when both authors were Jean Monnet Fellows at the European University Institute (Florence) where some of the experiments described in this paper were conducted. We thank the Institute for its hospitality and for assistance in running the experiments. We also thank and acknowledge the hospitality of the laboratories of the SFB 504 of the University of Mannheim and of the faculty of economics at the University of Pavia where further experiments were done. We thank Carluccio Bianchi, Martin Hellwig, Simon Hug, Tullio Jappelli, Ramon Marimon, Stephen Spear, Amy Verdun, and several seminar participants for helpful discussions.

†Via Cintia 26, Complesso Monte Sant’Angelo; I-80126 Napoli; bernasco@unipv.it

${ }^{\dagger} \mathrm{L}$ 13, 15; D-63131 Mannheim; Phonel +49-621-181-3447; Fax: +49-621-181-3451; oliver@kirchkamp.de
} 


\section{Introduction}

The inflationary impact of monetary policy is a classic theme in macroeconomics, which has long been investigated through theory and econometric studies. More recently it has also been the focus of an interesting series of experiments. Following the resurgence of interest of macroeconomists for theories of adaptive learning (see Evans and Honkapohja (1999), for a thorough review), Lim, Prescott and Sunder (1994), Marimon and Sunder (1993, 1994, 1995) and Marimon, Spear and Sunder (1993), all ran experiments to investigate whether the inflationary processes in overlapping generation economies (OLG) with multiple equilibria would be better explained by adaptive expectations or by the rational expectations hypothesis.

In the setting underlying the experiments, which closely mimics an OLG model studied theoretically by Sargent and Wallace (1987), Marcet and Sargent (1989), Bruno and Fisher (1990), monetary policy is public knowledge and subjects use money as a unique asset to transfer wealth across two periods. The model displays a well-known indeterminacy problem 1]: under any monetary policy, the economy has two stationary rational expectation solutions - a low (classical) inflation stationary state (ISS) and a high ISS - and a continuum of non-stationary rational expectations equilibria which reach the high ISS in the long run. On the other hand, stability of the 'adaptive dynamics' implies convergence towards the low ISS under a large class of adaptive learning rules and for a large set of initial conditions.

The inflation paths observed in a first wave of experiments (e.g. Marimon and Sunder $(1993,1994))$ documented wide convergence towards the stationary equilibrium with low inflation, giving substantial support to adaptive learning as a valuable theory of equilibrium selection.

Later, Marimon and Sunder (1995) in the same experimental setting compared the inflationary impacts of two classical monetary regimes.

Under the first regime, which Marimon and Sunder call the 'real deficit rule', the government fixes a constant level of real deficit and finances it through seigniorage (though government expenditure does not enter into agents' utilities). Such a rule may yield high inflation in some periods and low inflation in others. Under the second regime, called the 'money growth rule', the government fixes the rate of growth of the money supply and adjusts the level of seigniorage to satisfy its money growth rule. This rule may lead to a high government deficit in some periods and to a small one in others.

Although the two regimes correspond to different fiscal environments, in Marimon and Sunder's (1995) experiment the two rules were fixed so as to share the same steady state equilibrium and also to yield, in equilibrium, the same government revenue. The goal of the investigation was to test a classical conjecture, first suggested by Friedman (1948, 1960), that to stabilise inflation, a simple rule, such as constant growth of the money supply, may be better because it can more easily be learned, making it easier for agents to co-ordinate their behaviour.

Marimon and Sunder (1995) found weak support for this conjecture: price volatility observed in their experiments, rather than by differences in the monetary regimes is better

\footnotetext{
${ }^{1}$ The model is an OLG version of Cagan's model of hyper-inflation (Cagan 1956).
} 
explained by the stability properties of the adaptive learning rules which subjects seemed to adopt. They specifically found support for first-order adaptive expectations and showed theoretically that first-order adaptive expectations imply equivalence of the volatility of inflation under the two rules.

Here we submit Friedman's conjecture to further scrutiny, using an experimental setup that allows us to observe more details of subjects' behaviour and to study the process of expectations formation independently of that of actual saving decisions. We further try to make sure that subjects easily understand what is going on in their economy. We find that the two monetary rules are no longer equivalent, but differ significantly in terms of both the level and the volatility of inflation. Since we can observe more details of the subjects' decision-making process, we can relate the changes in the macroeconomic properties to changes in the microeconomic behaviours.

Different setups to model an OLG economy in an experiment are reported in the literature. Marimon, Spear and Sunder (1993) introduced a very straightforward procedure to assist subjects to make their optimal saving decisions. This procedure was later also used by Marimon and Sunder (1995): subjects are asked to make one inflation forecast for one period ahead (knowing past realized inflation), and then the computer software automatically computes and implements subjects' optimal saving, given that unique forecast and treating it as if it were certain 2 .

Individuals, however, may have reasons for deviating from this certainty equivalent behaviour and, more generally, from strict optimisation. Firstly, there is the possibility that agents do not hold point expectations, and react to the volatility of inflation with precautionary saving. Secondly, rather than proceeding to individual maximisation, agents may to some extent copy others believed to be better equipped to make good decisions. Thirdly, various other factors like inertia, small transactions costs (also interpreted in psychological terms), rules of thumb, may generate small deviations from optimality 3 .

We therefore made a few changes in designing our experimental set-up, which we considered important for understanding better the forces which may drive the inflationary processes of the two monetary rules. Let us emphasise three of these changes. Firstly, in our network economy subjects make both forecasts, receiving from the computer a suggestion for optimal saving, but then making their actual saving decisions. In this way, we can analyse whether and how actual differ from optimal decisions. Second, we do not restrict our subjects to hold quasi-point forecasts: our subjects can check the implication

\footnotetext{
${ }^{2}$ This procedure was also introduced to reduce part of the noise observed in earlier experiments with more elaborate setups. Lim, Prescott, Sunder (1994), for example, used oral double auctions to determine exchange rates in each period. It turned out that even with auctions lasting for five minutes in each single period markets did not clear. Later, they, and also Marimon and Sunder (1993), asked subjects to send a supply schedule to a walrasian auctioneer who then determined market clearing prices. This solved the problem of markets not being cleared, but still led to rather noisy prices. The noise was clearly reduced by the more direct optimality procedure used by Marimon and Sunder (1995). It is however worthwhile anticipating that, together with the noise, they also eliminated a considerable amount of saving above the optimum, i.e. over-saving, observed in their earlier experiments, which, as we shall emphasise throughout this paper, affect quite differently the inflationary processes of the two monetary regimes under study.

${ }^{3}$ All these effects may in particular be important under adaptive expectations, under which the actual law of motion of the economic systems typically differs, during the transitional process towards an equilibrium, from the law of motion as perceived by economic agents.
} 
of many forecasts for various periods ahead before making a final saving decision. This allows us to distinguish subjects whose forecasts in a given period vary little from others whose forecasts vary more and may perhaps generate higher savings. Third, in a further attempt to make our experimental environment descriptively richer, we introduce labels for monetary policies and make participants vote for monetary policies.

We alternately place the 'real deficit rule' and the 'money growth rule' under two different labels: we present to our subjects the experimental market as a market operating in the European Monetary Union; and we propose the two rules as implemented either by the Bundesbank or by the EU Commission. Besides making the experimental environment more interesting, and hence accativating the attention of the participants, our hypothesis was that labels could themselves affect subjects' expectations and the volatility of the inflation under the two rules. We conjectured that the 'Bundesbank label' might generate less inflation volatility than the 'EU Commission label'; but we find little support for this.

Anticipating briefly our results, regardless of the effect of labels, we first of all note that, like our precursors, we find convergence to the low ISS in most of our experimental economies. The actual transition dynamics, however, that we find around the low ISS equilibria are much more complex under both regimes and for all of our experimental economies than can be approximated by a first-order or by any other simple adaptive scheme. In particular, we find that the inflation rates under the real deficit regime are, on the average, lower than the inflation equilibrium levels and also than the average inflation rates observed under the revenue equivalent money growth rule; in support of Friedman's conjecture, the price is a greater inflation volatility under the real deficit regime than under the money growth rule.

The evidence we can explain with the characteristics of the saving decision processes which our subjects seem to follow. First of all, we find that actual saving rates differ significantly from the optimal saving decisions implied by individual forecasts: the latter enter in explanation of the former together with past average saving rates, in a convex combination which explains our findings rather well. Most importantly, we also find a significant amount of over-saving at individual and aggregate level, probably due to a form of precautionary saving: since the payoff functions given to our subjects imply that savings should increase to a mean preserving spread in the expected rate of inflation, and since with our setup we can measure the variance of individual forecasts, we find that uncertainty about the future (shown by forecasts with greater variance) explains oversaving as precautionary saving.

Over-saving is important because it is at the root of the trade-off between the two regimes implied by our findings. In particular, we will show that only under the real deficit regime increasing average saving rates yield decreasing inflation rates; but we will also show that stability of adaptive learning near the low ISS is negatively related to the inflation rates.

While from one perspective our findings seem to support Friedman's conjecture on the comparison between the two regimes, it must however be noted that from a different

\footnotetext{
${ }^{4}$ The rationale for the conjecture follows from some recent work on the theory of equilibrium selection in games, which emphasises the effect that 'labelling' and 'framing' (see e.g. Sugden (1995) and references quoted there) may have in helping agents to find their way towards an equilibrium.
} 
perspective they contrast with another hypothesis also advanced by Friedman in his Nobel lecture (Friedman 1977). There he suggested that a positive relation exists between the level of inflation and its volatility. Despite the fact that this second conjecture was formulated in a context of uncertainty of monetary regimes, rather than comparison of regimes, the policy trade-off is quite interesting; and we will discuss the issue commenting the results.

The rest of the paper is organised as follows. In section 2 we briefly review the theoretical OLG model which we investigate. In section 3 we specify the changes introduced in our experimental setup from previous studies and will give reasons for them. Details of the experiments we run in Florence (Italy), Mannheim (Germany) and Pavia (Italy) are given in section 4, the results and their implications in sections 5 and 6 A brief final section (Section 7) relates our findings to current research on models of adaptive learning and the role the latter may in general have in ranking monetary policies.

\section{A theoretical OLG model of saving, inflation and mon- etary policies}

We study a standard OLG model, in which fiat money is the only financial asset and government revenue is created through seigniorage. Each generation consists of $n$ agents and each agent of each generation lives for two periods. We call the first of these periods the 'entry' and the second, the 'exit' period. We use superscripts ${ }^{1}$ and ${ }^{2}$ to distinguish these two periods. An agent who enters in period $t$ will be called an agent of generation $t$ and has a two-period endowment of a unique perishable good $\left(\omega^{1}, \omega^{2}\right)$ with $\omega^{1}>\omega^{2}>0$. The agents' preferences over consumption $c_{t}^{1}$ and $c_{t}^{2}$ in the two periods are represented by the utility function

$$
u\left(c_{t}^{1}, c_{t}^{2}\right):=c_{t}^{1} c_{t}^{2} .
$$

Given a sequence of prices for the consumption good $\left\{p_{t}\right\}_{t}$, each agent of generation $t$ solves the problem:

$$
\begin{aligned}
& \max _{c_{t}^{1}, c_{t}^{2}} u\left(c_{t}^{1}, c_{t}^{2}\right) \\
& \text { s.t. } p_{t} \cdot\left(c_{t}^{1}-\omega^{1}\right)+p_{t+1} \cdot\left(c_{t}^{2}-\omega^{2}\right) \leq 0
\end{aligned}
$$

Thus, if the agent knew today's and tomorrow's price he would best save:

$$
s_{t}=\frac{1}{2}\left(\omega^{1}-\frac{p_{t+1}}{p_{t}} \omega^{2}\right)
$$

But, he does not know them. Assuming, however, that all the uncertainty of the agent reduces to hold a well defined price ratio expectation $\pi_{t+1}^{e}=E_{t-1}\left(p_{t+1} / p_{t}\right)$, and that the agent deals with this expectation as if it were certain, a general hypothesis sometimes called of certainty equivalent behaviour (see, e.g. Romer (1995, p. 246)), the optimal saving decision becomes

$$
s_{t}=\frac{1}{2}\left(\omega^{1}-\pi_{t+1}^{e} \omega^{2}\right)
$$


The equilibrium price for any period $t$ is such that the per capita aggregate supply $s_{t}$ equals the per capita aggregate (real) money supply $m_{t}$ :

$$
s_{t}=m_{t}
$$

The per capita aggregate money supply $m_{t}$ depends on the monetary regime. We consider two regimes. Under the first, the 'real deficit' regime, the political authority fixes a constant per capita level of real deficit $d$ and finances it through seigniorage; under the second, the 'money growth' regime, the monetary authority allows money to grow by a constant factor of $\mu$ and adjusts the level of seigniorage to satisfy the monetary target. In neither model considered here are the seigniorage proceeds returned to consumers. By setting $\mu=1$ when $d \neq 0$ and $d=0$ when $\mu>1$, both regimes can be represented by the following equation:

$$
m_{t}=\mu m_{t-1} \frac{p_{t-1}}{p_{t}}+d
$$

The real deficit regime, which has been studied experimentally by Marimon and Sunder (1993, 1994), corresponds closely to Cagan's model of hyper-inflation (Cagan 1956); whereas the money growth regime, experimentally compared with the first by Marimon and Sunder (1995), implements Friedman's rule of a constant growth of the money supply.

Although the two regimes describe different monetary-fiscal environments, they may have the same steady state equilibrium. To see this, following Marimon and Sunder (1995, p. 118), equations 5 to 7 give the equilibrium map:

$$
\Phi\left(\pi_{t+1}^{e}, \pi_{t}^{e}, \pi_{t}\right)=0
$$

i.e.

$$
\pi_{t+1}^{e}-(b-e d)+\mu \frac{b-\pi_{t}^{e}}{\pi_{t}}=0
$$

where $\pi_{t}=p_{t} / p_{t-1}, b=\omega^{1} / \omega^{2}$ and $e=2 / \omega^{2}$. Given that, for $\pi_{t}^{e} \neq b, \partial_{3} \Phi(\cdot)=\left(\pi_{t}^{e}-\right.$ $b) / \pi_{t}^{2}=0$, actual inflation can be expressed as a function of expected inflation for the current and the following period:

$$
\pi_{t}=\mu \frac{b-\pi_{t}^{e}}{b-\pi_{t+1}^{e}-e d}
$$

Equation 10 describes the actual law of motion of $\pi_{t}$, given expectations and the monetary regime. Assuming the rational expectations hypothesis $\pi_{t}^{e}=\pi_{t}$, it coincides with the equilibrium dynamics of the economy $\pi_{t+1}=R_{(\mu, d)}\left(\pi_{t}\right)$ :

$$
\pi_{t+1}=(b+\mu-e d)-\mu \frac{b}{\pi_{t}}
$$

For $(b-e d+\mu)^{2}>4 \mu b$, there are two solutions satisfying the stationary condition $\Phi\left(\pi_{t+1}^{e}, \pi_{t}^{e}, \pi_{t}\right)=05$ Under the money growth rule, i.e. when $d=0$ and $\mu>1$, the two are given by $\pi^{L}=\mu$ and $\pi^{H}=b$, where, for $\mu<b, \pi^{L}$ identifies the low ISS (inflation stationary state), and $\pi^{H}$ defines the high ISS. 


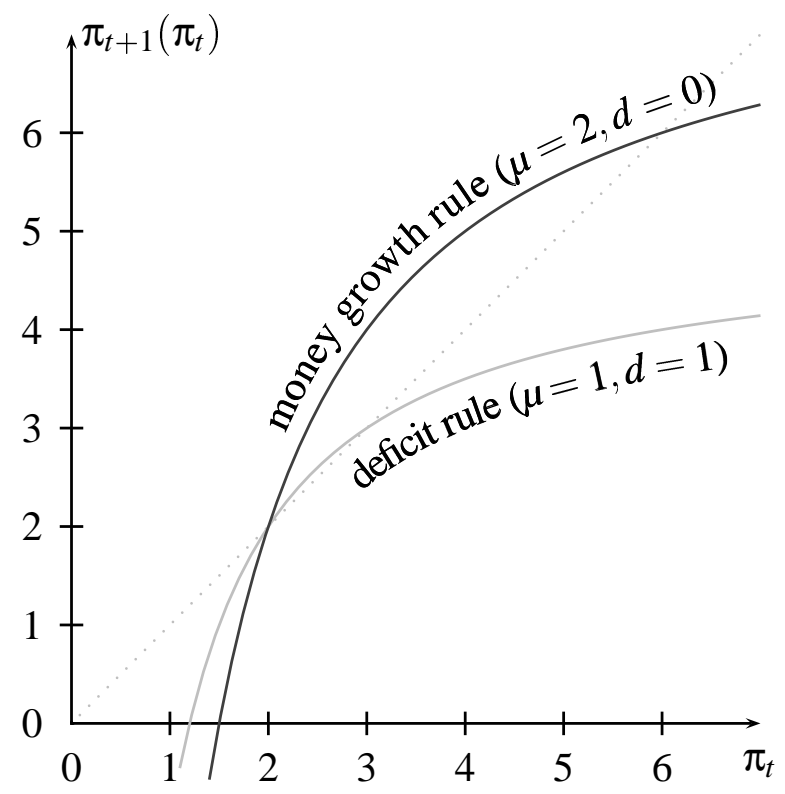

(From Marimon and Sunder, 1995, p. 120)

Figure 1: Two $R_{(\mu, d)}$ maps sharing the same low ISS

Figure 1, from Marimon and Sunder (1995, p. 120), shows two $R_{(\mu, d)}(\cdot)$ maps constructed from such a system of parameter values. The figure may help to understand some stability properties of the rational expectations equilibria.

The dotted line shows $\pi_{t+1}\left(\pi_{t}\right)=\pi_{t}$. The two hyperbolas represent the mapping from $\pi_{t}$ to $\pi_{t+1}$ for the two different monetary regimes. Assume that $(b-e d+\mu)^{2}>4 \mu b$, thus, we have two stationary solutions. Clearly, starting from an initial inflation rate $\pi_{0} \in\left(\pi^{L}, \pi^{H}\right)$, the rational expectations dynamic will end at $\pi_{t} \rightarrow \pi^{H}$ in the long run. This, however, is only necessarily the case for rational expectations. In recent years several authors have analysed and suggested different adaptive learning rules as selection procedures in models with multiple rational expectation equilibria. Very much in the tradition of Cagan (1956) and Friedman (1957), the hypothesis of adaptive learning essentially is that economic agents form and coordinate their beliefs by adjusting adaptively to past experience. This adaptive adjustment can of course operate on parameters of the model as well as on realizations, like prices, inflation or average saving levels. We focus here on adaptive learning of realizations, i.e. inflation or average saving levels. For example, first-order adaptive learning of inflation can be expressed as follows:

$$
\pi_{t+1}^{e}=\pi_{t}^{e}+\alpha_{t} \cdot\left(\pi_{t-1}-\pi_{t}^{e}\right)
$$

In the context of the present OLG model, a large class of adaptive learning algorithms (encompassed by the first-order adaptive scheme) will for a large class of initial condi-

\footnotetext{
${ }^{5}$ For the case $\omega^{2} \rightarrow 0$ we have $b \rightarrow \infty$ and only one stationary solution $\pi=\mu \omega^{1} /\left(\omega^{1}-2 d\right)$.
} 
tions converge on the low ISS6 (see e.g. Marcet and Sargent (1989), Marimon and Sunder (1995), Evans, Honkapohja and Marimon (1996). See also review and references in Sargent (1993) and Marimon (1997)). This convergence 7 has important policy implications. There is the 'high inflation trap' (Bruno and Fisher (1990)): the existence of the dual equilibria - a reflection of the so-called 'bad Laffer curve in the inflation tax rate' means that an economy may be stuck in the high inflationary equilibria, when with the same fiscal policy it could be at a lower, Pareto-optimal, inflation rate. In addition, the comparative dynamics of the two equilibria moves in the opposite directions: in particular (see equation [10), only under the low inflation equilibrium can the 'classical' prescription to reduce deficit in order to stabilise prices be recommended; under the high inflationary equilibrium, a permanent decrease in $d$ causes the inflation rate to rise because the economy is on the wrong side of the Laffer curve. In this respect, adaptive learning (with convergence to the low inflation equilibrium as a consequence) supports the 'classical' policy prescription.

On the other hand, when we ask which monetary regime might better stabilise inflation, the adaptive learning hypothesis per se is not very selective. To see this (see also Marimon and Sunder (1995, p. 122)), simply substitute equation 10 into equation 12 , linearise at $\pi_{L}$, and re-write $\pi_{\tau}^{e}=\pi_{L}+\delta_{\tau}$, to obtain

$$
\delta_{t+1}=-\pi_{L}+(1-\alpha)\left(\pi_{L}+\delta_{t}\right)+\frac{\pi_{L} \alpha \mu\left(-\omega_{1}+\left(\pi_{L}+\delta_{t-1}\right) \omega_{2}\right)}{-\mu \omega_{1}+\pi_{L}\left(\mu+\delta_{t}\right) \omega_{2}}
$$

which gives us the equilibrium map

$$
\left(\begin{array}{c}
\delta_{t+1} \\
\delta_{t}
\end{array}\right)=\left(\begin{array}{cc}
1-\alpha+\frac{\pi_{L}^{2} \alpha \omega_{2}}{\mu \omega_{1}-\pi_{L} \mu \omega_{2}} & \frac{\pi_{L} \alpha \omega_{2}}{-\omega_{1}+\pi_{L} \omega_{2}} \\
1 & 0
\end{array}\right)\left(\begin{array}{c}
\delta_{t} \\
\delta_{t-1}
\end{array}\right)
$$

The eigenvalues of the matrix in 14 describe the stability of the dynamic process. With complex eigenvalues, the law of motion of the rate of inflation is characterised by cyclic fluctuations around $\pi_{L}$; and stability depends only on the contraction factor:

$$
r(\alpha)=\frac{\pi_{L} \alpha \omega_{2}}{\omega_{1}-\pi_{L} \omega_{2}}
$$

In particular, the greater the expression, the more likely the system is to be stable 8 . Since, however, the expression does not depend on the parameters of the monetary rule,

\footnotetext{
${ }^{6}$ Note, however, that $\pi \rightarrow \infty$ is also an attractor of the adaptive dynamics under these conditions.

${ }^{7}$ Despite the convergence, it is however important to appreciate that, contrary to the case of rational expectations, under adaptive expectations, the actual law of motion of $\pi_{t}$, given by equation 10 is no longer consistent with the perceived law of motion from equation 12. Under this perspective, the assumption of no-uncertainty underlying the theoretical OLG model may appear even stronger.

${ }^{8}$ More specifically, the eigenvalues of the matrix in 14 are:

$$
\begin{aligned}
\lambda^{1}(\alpha) \cdot \lambda^{2}(\alpha) & =\frac{\pi_{L} \alpha \omega_{2}}{\omega_{1}-\pi_{L} \omega_{2}} \\
\lambda^{1}(\alpha)+\lambda^{2}(\alpha) & =(1-\alpha)+\frac{\pi_{L}^{2} \alpha \omega_{2}}{\mu \omega_{1}-\pi_{L} \mu \omega_{2}}
\end{aligned}
$$

If $\lambda(\alpha)$ are complex, that is if $\lambda(\alpha)=x \pm y i$, then whether the system is stable or not depends on whether $\sqrt{\left(x^{2}+y^{2}\right)}=\sqrt{\frac{\pi_{L} \alpha \omega_{2}}{\omega_{1}-\pi_{L} \omega_{2}}}$ is greater than or equal to one.
} 
it follows that, close to the low inflation equilibrium, the two rules share the same stability properties. Thus, somewhat paradoxically against Friedman's conjecture, under first-order adaptive learning neither regime can be preferred to the other.

The series of experiments conducted by Marimon and Sunder $(1993,1994,1995)$ give substantial support to the first-order adaptive learning and to the corollaries mentioned above. In the rest of the paper we describe our experimental set-up, how it differs from our precursors, and report results not quite conforming with the previous evidence.

\section{An experimental setting for OLG models}

Preparing an experimental environment for the theoretical models described in the previous section requires consideration of several complex implementation problems. We have adapted the general implementation strategy of our precursors, which was based on the following basic design.

\subsection{The experimental environment}

A typical experimental environment simulates a very simple market. In the market, subjects can buy and sell a commodity that we call chips in a sequence of market periods. There is a fixed number $(N)$ of participants and, for each market period, each participant has a specific role: $n$ subjects enter the market and act as young consumers; $n$ act as old consumers and leave the market at the end of the period; the remaining $N-2 n$ stay outside and await their turn to enter as young consumers. A young consumer in one period becomes an old consumer in the next.

When young consumers enter the market, they receive their $\omega^{1}$ endowment of chips. They may consume ('eat') some of these chips instantly (in the amount $c^{1}$ ) and sell the remaining chips to old consumers and to the government (in the quantity $S=\omega^{1}-c^{1}$ ). In return for the chips they sell they receive experimental money, which is saved for their old age in the next period. In old age consumers 'eat' a total number of chips given by $c^{2}=\omega^{2}+S p_{t} / p_{t+1}$.

The number of chips 'eaten' in both the entry and the exit periods, $c_{1}$ and $c_{2}$ respectively, determines the payoff in Italian Lire or German Marks for participating in the market, according to a linear transformation $\lambda \cdot c^{1} \cdot c^{2}-\kappa$. Subjects learn their payoff in local currency from the current round immediately after the market clears.

Subjects enter and leave the market more than once during an experimental session and their payoff for each market participation accumulates (the total is paid at the end of the experiment). When, however, a subject re-enters the market it is not possible to access the account accumulated from previous participation: the subject re-enters the market as a newborn? 9 .

\footnotetext{
${ }^{9}$ In the words of Marimon and Sunder (1993, p. 1076), it is as if "subjects were living several 'lives' over the many periods of a particular economy". They (Lemma 1, p. 1085) also show that this repeated participation does not cause departure from the OLG model, in the sense that if strategic behaviours (in violation of the competitive assumption underlying the theoretical OLG model) arise at all in the experimental market, this is due to the fewness of the subjects and not to the repeated participation per se. On the contrary, the repeated entry of the same subjects into the economy can be particularly useful to study how learning and
} 


\subsection{A WWW Interface for the experiment}

In our experimental design, market transactions between agents are administered by a networked software program accessed by a WWW-Browser. Figure 2 shows the typical interface for the experiment. The main task subjects have to perform (see top half of the figure) is a saving decision when they are young consumers, i.e. in their entry periods.

Subjects are also asked to make a saving recommendation in periods when they are old or outside the market. To do that they use the same interface they use otherwise for saving decisions when they are young. The only difference is that they are told that payoffs from saving recommendations (on the gray background in the 'History' table of the figure) do not count for the final payoff. Subjects are told that they may benefit from giving serious consideration to saving recommendations while learning and practising with the software and with the economy. As it turns out, the behaviour of 'old' or 'idle' subjects is very similar to that of 'young' subjects.

\subsubsection{The chips supply and demand, and the monetary regimes}

In each market period, the individual savings of only the young agents are added by the computer to determine the goods supply.

The aggregate money supply is given by the sum of the real cash balance in the hands of the old plus the demand for chips for public expenditure (which, consistently with the theoretical model, does not enter into the subjects' payoff functions). Under the real deficit regime, this residual public expenditure is given by $d$ chips per head bought in each period at the market clearing price; whereas under the money growth regime the public demand is adjusted for growth in the amount of money in circulation at a constant factor of $\mu$ in each period.

Which of the two regimes is in force is determined at the beginning of each experimental session by election. Subjects are told that they will participate in a simulated market operating in the EMU and are informed about the two monetary regimes. The mapping of the two regimes to labels that describe the central bank which controls the monetary policy is fixed for each experiment. Labels may either be EU-Commission for one monetary regime and Bundesbank 10 for the other or two neutral labels 'red' and 'blue' for the two regimes. Before making any saving decisions subjects are asked to vote for a regime. In some sections the election determines the monetary regime. In some sessions the regime is predetermined. Subjects know this, though they do not know in which session the regime is predetermined.

The market clearing price is determined in each period by the computer program as the residual between goods supply and money supply. The resulting allocations, the rate of inflation and the average saving in the economy are displayed in the 'History' table on the computer screen (figure 2).

With no announcement in advance, at the end of some period of the experimental session participants are informed which was the last period of the session. Chips 'eaten'

experience may affect subjects' decisions, because if it is true that "assets cannot be carried from one 'life' to the next, but memory and experience obviously are" (Marimon and Sunder (1993, p. 1076)).

${ }^{10}$ In Florence we used EU-Commission and EURO-Bank as labels, pointing out that the EURO-Bank would be particularly independent, similar to the Bundesbank. 


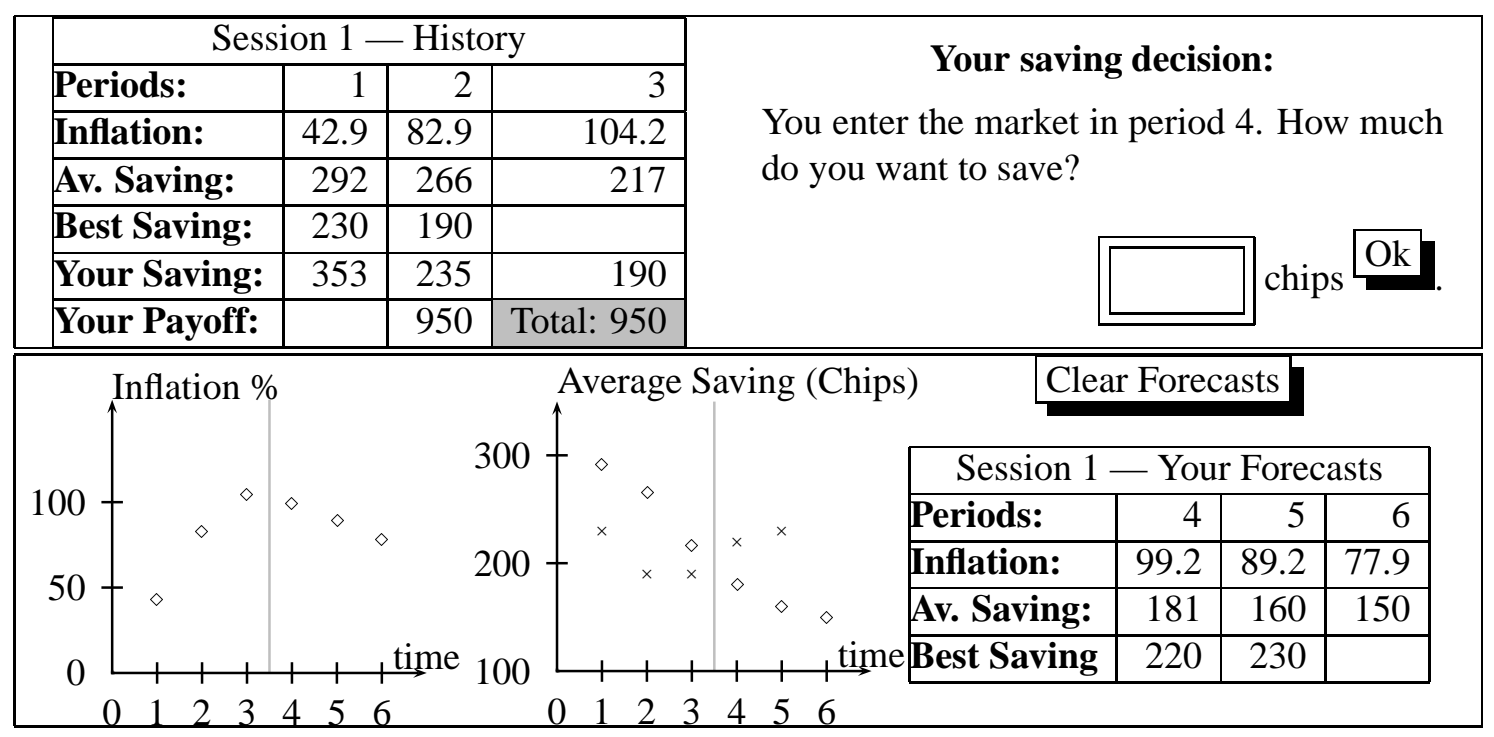

A demo of the experiment may be accessed at http://www.sfb504.uni-mannheim.de/ex/register.

Figure 2: The terminal interface

or saved in the last period by young consumers have no value.

\subsubsection{A specialised calculator}

Apart from the novelty and easy accessibility of the www interface, the main innovation in our experiment is a 'specialised calculator' to assist subjects in their saving decisions. The calculator consists of two diagrams, one for inflation and one for average saving, and a table (see the bottom part of the computer screen of figure 22). Whenever they wished, subjects could make forecasts for either the rate of inflation or for average saving by directly clicking in either diagram at that level of inflation or of average saving forecast for a given period. Depending on the forecast, the program computes the saving decision which maximises the payoff and displays the result in the table. Subjects may then decide to use the suggested saving decision; they may change their forecast to obtain a new saving suggestion; they may also explore the future, making forecasts for several periods ahead; or they may disregard the suggestions of the computer and make whichever saving decision they wish.

In contrast to this setup, most previous experiments have not separated the process of expectations formation from that of actual saving decisions. For example, in Marimon and Sunder (1995) subjects were asked to submit a unique inflation forecast in each market period, which was then used by the computer to determine automatically the individual optimal saving. While this procedure adheres more strictly to the theoretical model outlined in the previous section, since it directly imposes the assumption of certainty equivalent on subjects' behaviour, it may however be inconsistent with the way people actually make their saving decisions. With our approach, we particularly wanted 


\begin{tabular}{|l|cc|cc|cc|cc|cc|}
\cline { 2 - 12 } \multicolumn{1}{c|}{} & \multicolumn{2}{c|}{ Parameters } & \multicolumn{2}{c|}{ Low ISS } & \multicolumn{2}{c|}{ High ISS } & \multicolumn{2}{c|}{ Eigenvalues } & \multicolumn{2}{c|}{ Contraction } \\
\hline Regime & $d / \omega_{1}$ & $\mu$ & $s_{L} / \omega_{1}$ & $\pi_{L}$ & $s_{L} / \omega_{1}$ & $\pi_{H}$ & $\lambda(1)$ & $\lambda(.5)$ & $r(1)$ & $r(.5)$ \\
\hline Money growth & 0 & 2.27 & .31 & 2.27 & 0 & 6 & $.31 \pm .72 i$ & $.40 \pm .39 i$ & .78 & .55 \\
\hline Real deficit & .17 & 0 & .31 & 2.27 & .28 & 2.63 & $.69 \pm .36 i$ & $.37 ; .83$ & .78 & - \\
\hline
\end{tabular}

Table 1: Parameters and inflation and saving levels

to investigate two possible ways of deviating from the hypothesis of certainty equivalent. First, in order to address the difficult problem they are facing, some subjects, rather than making expectations, may simply find it easier to follow what they expect other people are doing, looking perhaps at what others have done in the past. In this case we might expect more inertia in saving behaviours than that implied by strict maximisation. Second, even if subjects do actually have expectations, they may not necessarily hold point expectations. They may reason in terms of an interval of possible expectation values and hence react to the relative uncertainty with precautionary savings. As it turns out, both types of behaviour are well documented in our results; and, as we shall see, they have important implications for the inflationary impact of the two monetary regimes.

\section{Experiments in Florence, Mannheim and Pavia}

With 13 groups of subjects, involving a total of 204 participants, we carried out 41 different experimental economies in Florence (Italy), Mannheim (Germany) and Pavia (Italy). Participants in Florence were Ph.D. students, most of them in Economics; in Mannheim they were undergraduates from faculties like engineering, social sciences and business administration; in Pavia they were undergraduates, mostly studying economics.

In all three places we tried to implement as many combinations of parameters as possible. In each place we studied economies which differed with respect to monetary regimes and labels. We also varied the number of periods played in each session (in particular to avoid an end-game effect) and the nominal initial endowment $\omega_{1}$ (to make communication among different groups of subjects more difficult). For the two regimes we study, Table 1 summarises the equilibrium values implied by the parameters we choose. (A more detailed list of the experiments is given in appendix $\mathrm{A}$.

These values accomplish two specific objectives we had in mind when we decided to conduct the experiments. Firstly, consistent with the theoretical model of section 2, the two regimes are fully comparable in the sense that they both have the same low ISS inflation rate $\left(\pi_{L}=2.27414\right)$ and the same saving rate $\left(s_{L}=0.310488 \cdot \omega_{1}\right)$; they allow collection of the same government revenue $\left(0.173958 \cdot \omega_{1}\right)$ (though they of course differ in the high ISS), and they share, under first-order adaptive expectations (i.e. with $\alpha$ close to one), the same stability properties $(r(1)=0,78)$. Secondly, in order to facilitate comparison, our experimental economies are very similar to those in the literature, in particular in Marimon and Sunder (1995); though none of the previously studied economies was exactly equivalent in terms of both low steady states and stability properties of the two monetary rules 11 .

\footnotetext{
${ }^{11}$ As a further objective, we wanted to have a 'challenging' setup, in the sense that we wanted high
} 
In the following section we present the results mechanically, leaving their discussion to a subsequent section. We do it in four steps: we start from the macro evidence, looking firstly at the average levels of inflation and saving, and secondly at the volatility of the economies; we move then to micro behaviours, beginning from the process of expectations formation, to conclude with the analysis of the actual saving decisions. The presentation of the results will refer to values which are normalised relative to the low ISS: inflation $\pi_{L}$ is normalised to 100 and saving $s_{L}$ is normalised to 1 . Thus the high ISS is $\pi^{H}=116, s=0.902$ under the constant real deficit rule and $\pi^{H}=263, s=0$ under the constant money growth rule. We give here a compact version of the results; a more detailed analysis can be found in Bernasconi and Kirchkamp, (1998), with a full account of the whole experimental procedure, including instructions and details of introductory experimental sessions.

\section{Results}

\subsection{The macro evidence}

\subsubsection{The amount of inflation and saving}

It is well established (Marimon and Sunder 1993, Marimon and Sunder 1994, Marimon and Sunder 1995) that in this setup subjects converge closely to the low-inflationequilibrium. Figure 3 shows the distributions of inflation and average saving levels in all our experiments which confirm this finding: both distributions settle around the low ISS equilibrium. Neither of the two, however, is symmetrically centered around the equilibrium values: the distribution of saving lean towards higher values and that of inflation towards lower values.

Figure 4 illustrating how the levels of inflation and saving develop over time in all our experimental economies, shows that the two biases do not depend on the evolution of the economies over time: average saving is somewhat greater than the equilibrium value and inflation is lower throughout all periods. (In the figure, boxes denote 25\%, 50\% and $75 \%$ quartiles, the upper whisker stretches to the highest data point that is still smaller than the $75 \%$ quartile, plus 1.5 times the difference between the $75 \%$ quartile and the $25 \%$ quartile. The lower whisker is constructed accordingly. Points outside the whisker are marked by circles).

To start to analyse which factors, among those we varied through the experiments, might have caused the above-mentioned departures from equilibrium values, Figures 5 and 6 illustrate how the levels of inflation and saving vary with places, monetary rules, and labels attached to monetary rules. The pictorial evidence confirms what we also

inflation and equilibria close together. Thus, while there is an upper border for the low ISS $\pi_{L} \leq \sqrt{\omega_{1} / \omega_{2}}$ (as long as there is an equivalent real deficit rule) we attempted to approach this border closely. In view of that, we have chosen $\omega_{1} / \omega_{2}=6$ (to be consistent with most of the previous experiments), and $d=$ $167 / 160 \cdot \omega_{2}$. These values almost mark an upper boundary: $d=\left(\sqrt{\omega_{1} / \omega_{2}}-1\right)^{2} / 2 \approx 168.082 / 160 \cdot \omega_{2}$ turns out to be the highest sustainable deficit. (The slightly higher value $d=168 / 160 \cdot \omega_{2}$ we might have chosen, would give the focal number $\left(\pi_{L}=5 / 2\right)$, which subjects could choose in the experiment because it's focal, and not because is an equilibrium). 

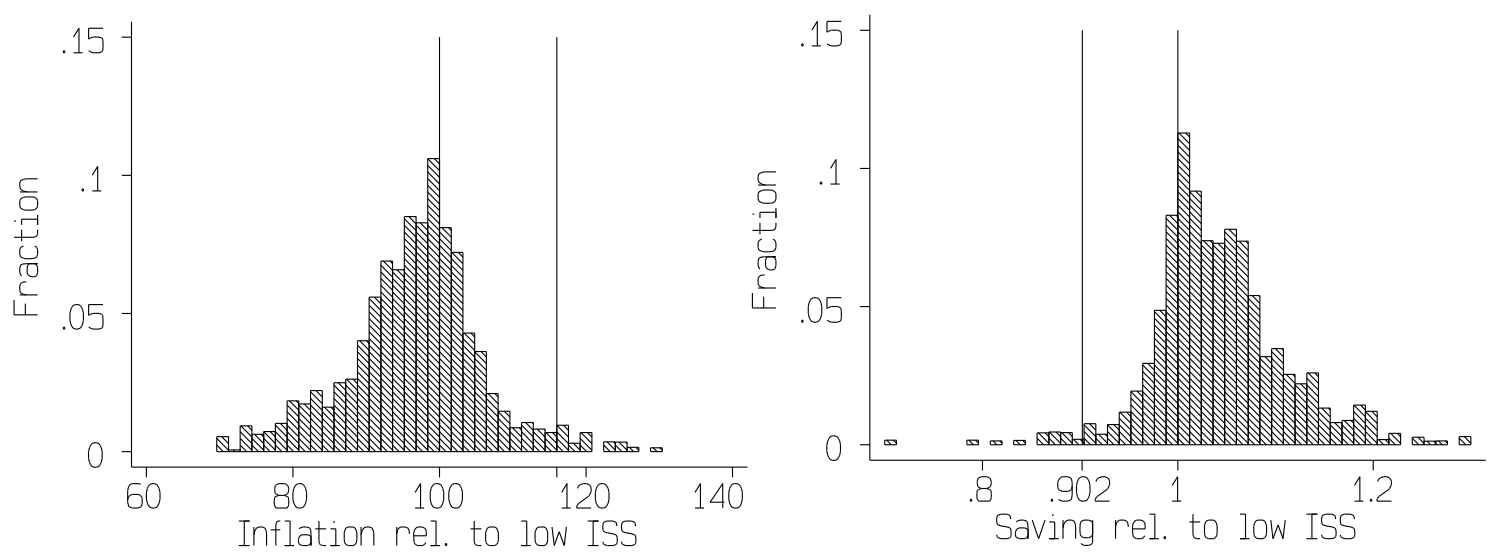

The left diagram shows inflation, the right one shows saving for all experiments.

Figure 3: Distribution of inflation and average saving levels

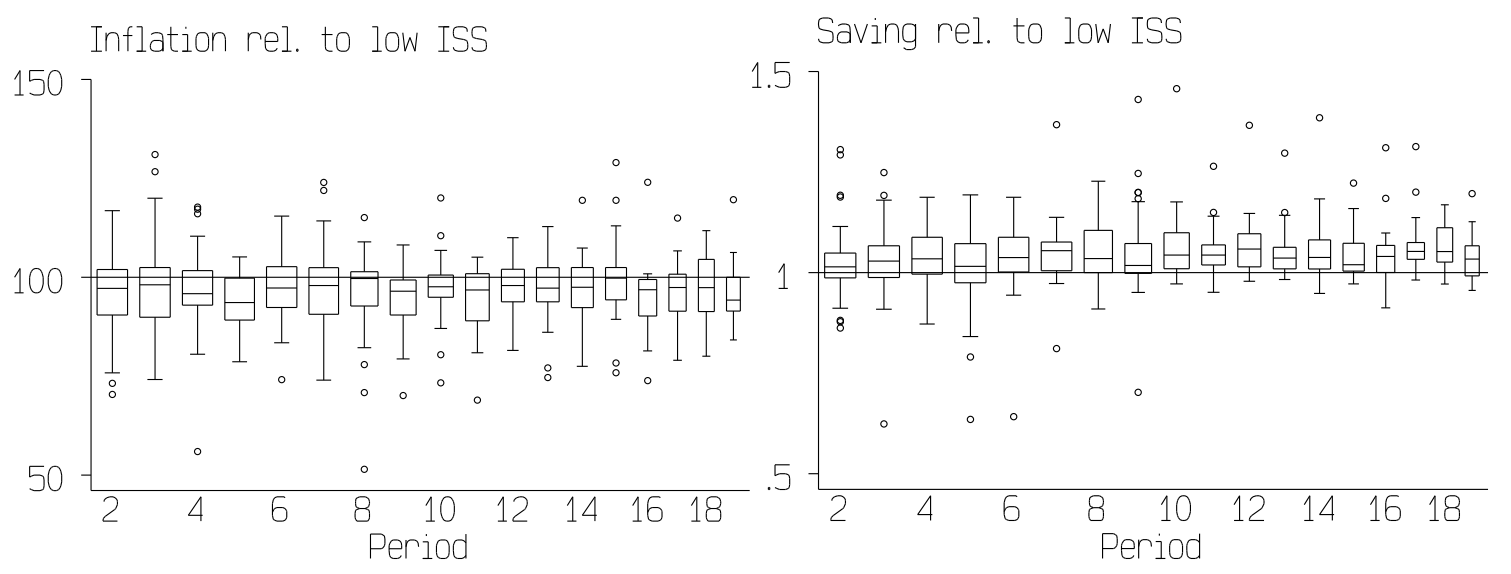

The left diagram shows inflation, the right one shows saving for all experiments.

Figure 4: Development of inflation and saving over time 


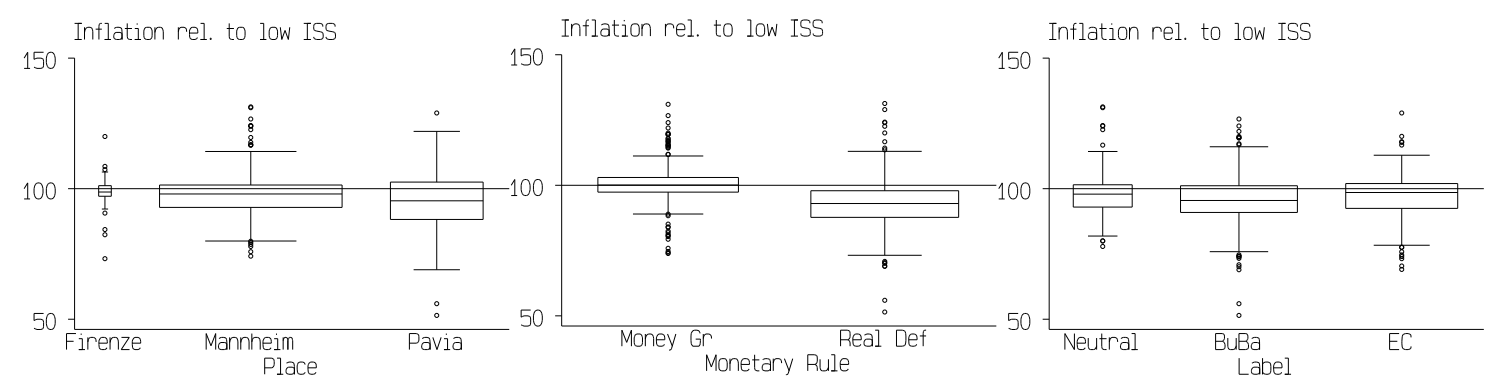

Figure 5: Inflation depending on place, monetary rule, and label.

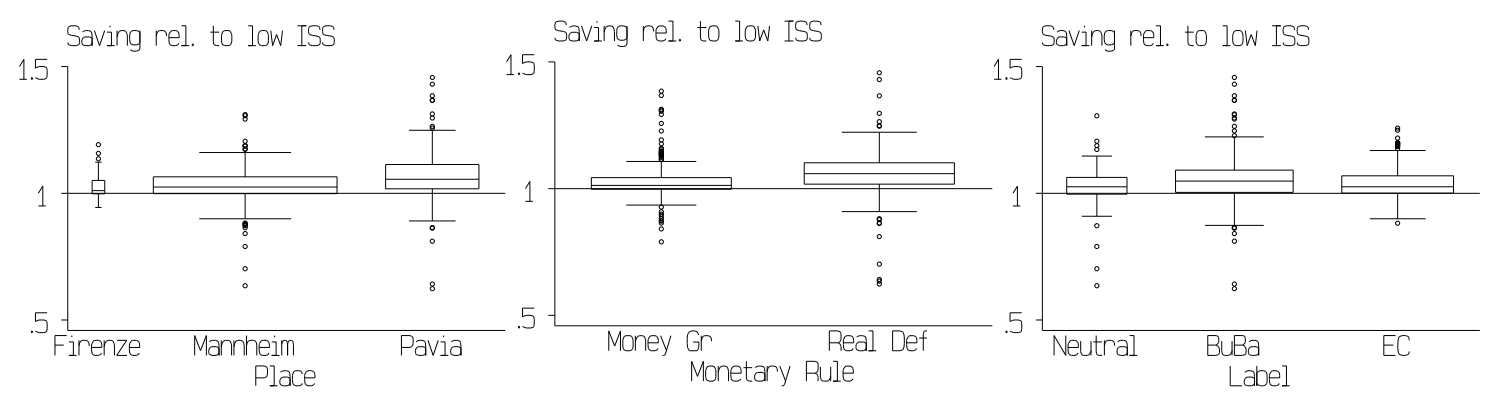

Figure 6: Saving depending on place, monetary rule and label.

tested from OLS regressions (available in our working paper Bernasconi and Kirchkamp (1998)). While we find no significant or systematic difference in the results depending on the places or on the labels, we find a significant and persistent effect in all places and under all labels for the monetary rules: the constant real deficit regime leads to less inflation and greater average saving than the constant money growth regime.

\subsubsection{Inflation volatility and Friedman's conjecture}

The central question underlying the experimental comparison of the two monetary regimes was to investigate Friedman's conjecture $(1948,1960)$ that a constant growth of the money supply stabilises inflation better than a constant real deficit rule, when the two regimes yield the same government revenues. To investigate this conjecture, we look at three different measures for volatility: two objective, an absolute one $\left(v_{\mathrm{oa}}=\ln \left|\pi_{t}-\pi_{t-1}\right|\right)$ and a relative one $\left(v_{\text {or }}=\ln \ln ^{2}\left(\pi_{t} / \pi_{t-1}\right)\right)$; and one subjective, $v_{s}=\ln \left(\sigma\left(\pi^{e}\right) / \overline{\pi^{e}}\right)$, where $\sigma\left(\pi^{e}\right)$ denotes the standard deviation of a subject's inflation forecasts and $\overline{\pi^{e}}$ the mean of these forecasts. In all cases we take logs to reduce skewness. The cumulative distributions are shown for the two regimes in figure 7

The use of a subjective measure, i.e. a measure of how volatility is perceived by the single individual, is specifically new and is only permitted by the novelty of our experimental approach. Since we are able to observe several forecasts by an individual for a given period, we can calculate the variance of the individual's forecasts for the period. If these forecasts are centered very closely around a single level, the individual might be feeling in a relatively stable situation. If, however, forecasts are scattered over a large interval, the individual is apparently less certain about the situation of the economy, which we interpret as the perception of a more volatile situation. 

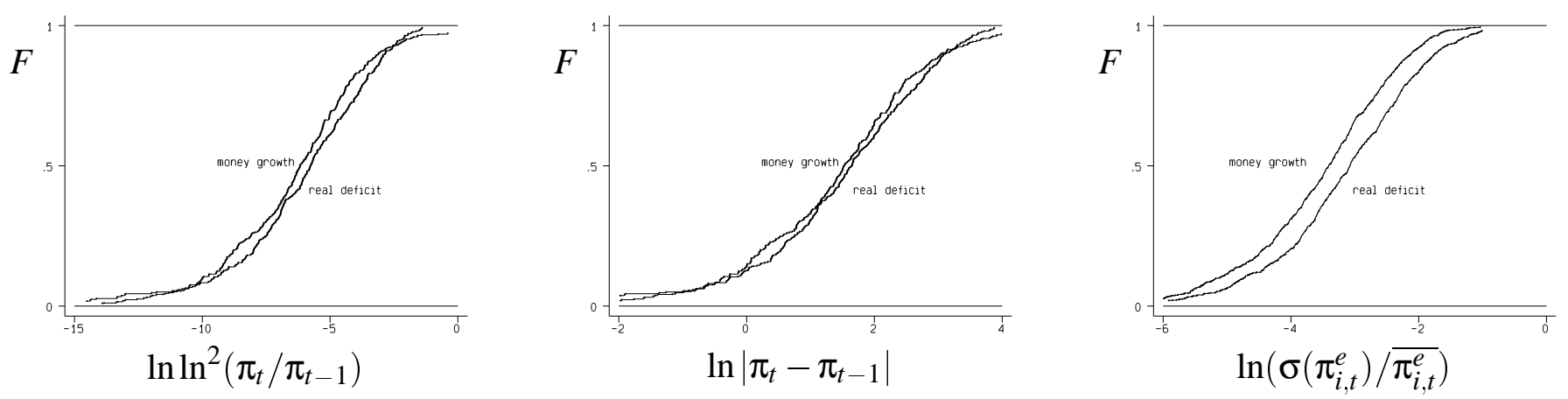

Figure 7: Cumulative distribution of different measures of volatility of inflation.

We ran several regressions, relating our three measures of inflation volatility to monetary rules, labels, places of the experiments, sessions. Table 2 summarises the regressions. While we find no significant effect for any other parameter studied, we observe that the effect of the monetary rule is present in all our experimental economies: specifically, we find that, regardless which indicator we consider, the constant real deficit rule (coded as 'deficit' in the table) always leads to more inflation volatility than the constant money growth rule.

Thus, in contrast to Marimon and Sunder (1995), our evidence apparently gives some support to Friedman's conjecture.

\subsection{Evidence on micro behaviour}

\subsubsection{Formation of forecasts}

Seeking the reasons for this difference in the results at micro level, we consider the process of expectations formation. We recall that with first-order adaptive expectations, and assuming strict optimisation and no-uncertainty, the constant money growth rule and the constant real deficit rule exhibit the same volatility as long as we are close to the low ISS.

Marimon and Sunder (1995) found substantial support for first-order adaptive expectations. Here we conduct a simple but direct test, to check whether adaptive learning in general and first-order adaptive expectations in particular are valid in our environment too.

We estimate for each period separately the equation:

$$
\pi_{t+1}^{e}=\alpha_{t} \pi_{t-1}+\beta_{t} \pi_{t}^{e}+c_{t}
$$

where the constant $c$ should be 0 for first-order adaptive learning. (The estimation are made separately for different periods. Hence the error term cannot be correlated with any of the $\pi$ 's). The development of the coefficients over time is described in Figure $8, c$ is not zero, but cycles around some positive value.

Our interpretation is that subjects have some sort of adaptive expectations, though there seems to be more inertia in subjects' adaptive learning rules than can be due to first-order adaptive learning alone 12

\footnotetext{
${ }^{12}$ Also Marimon, Spear and Sunder (1993) found some support for second order schemes. We also tested
} 


\begin{tabular}{|c|cccccrr|}
\hline \multicolumn{7}{|l|}{ Estimation of objective relative volatility $v_{\text {or }}=\beta_{\text {deficit }}+c$} \\
$v_{\text {or }}=\ln \ln ^{2}\left(\pi_{t} / \pi_{t-1}\right)$ & $\beta$ & $\sigma_{\beta}$ & $t$ & $P>|t|$ & $95 \%$ conf. interval \\
\hline \hline All experiments & & & & & \multicolumn{2}{c|}{727 observations } \\
deficit & .6200389 & .2321794 & 2.671 & 0.008 & .1642148 & 1.075863 \\
$c$ & -6.344855 & .1685217 & -37.650 & 0.000 & -6.675704 & -6.014006 \\
\hline
\end{tabular}

\begin{tabular}{|c|ccccccr|}
\hline \multicolumn{2}{|c|}{ Estimation of objective absolute volatility $v_{\mathrm{oa}}=\beta_{\text {deficit }}+c$} \\
$\mathrm{v}_{\mathrm{oa}}=\ln \left|\pi_{t}-\pi_{t-1}\right|$ & $\beta$ & $\sigma_{\beta}$ & $t$ & $P>|t|$ & $95 \%$ conf. interval \\
\hline \hline All experiments & & & & & \multicolumn{2}{c|}{727 observations } \\
deficit & .3094842 & .1189526 & 2.602 & 0.009 & .0759516 & .5430168 \\
$c$ & 1.405345 & .0863388 & 16.277 & 0.000 & 1.235841 & 1.574849 \\
\hline
\end{tabular}

\begin{tabular}{|c|c|c|c|c|c|c|}
\hline \multicolumn{7}{|c|}{ Estimation of subjective volatility $v_{s}=\beta_{v_{\mathrm{or}}} v_{\mathrm{or}}+\beta_{\text {deficit }}+\beta_{\mathrm{BuBa}}+\beta_{\mathrm{EC}}+c$} \\
\hline$v_{s}$ & $\beta$ & $\sigma_{\beta}$ & $t$ & $P>|t|$ & $95 \%$ con & interval \\
\hline \multicolumn{5}{|l|}{ All experiments } & \multicolumn{2}{|c|}{ 1808 observations } \\
\hline$v_{\text {or }}$ & .0948404 & .009629 & 9.849 & 0.000 & .0759552 & .1137256 \\
\hline deficit & .3779502 & .0607352 & 6.223 & 0.000 & .2588314 & .497069 \\
\hline $\mathrm{BuBa}$ & -.1558654 & .0756481 & -2.060 & 0.040 & -.3042325 & -.0074982 \\
\hline $\mathrm{EC}$ & -.1727994 & .0764621 & -2.260 & 0.024 & -.322763 & -.0228358 \\
\hline$c$ & -2.839546 & .0895649 & -31.704 & 0.000 & -3.015208 & -2.663885 \\
\hline
\end{tabular}

$\beta_{\text {deficit }}$ is a dummy variable that is one for the constant real deficit rule, $\beta_{\mathrm{BuBa}}$ is a dummy variable that is one for regimes labeled 'Bundesbank', $\beta_{\mathrm{EC}}$ is a dummy variable that is one for regimes labeled 'EU Commission', $c$ is a constant included in the regression.

Table 2: Determinants of objective and subjective volatility

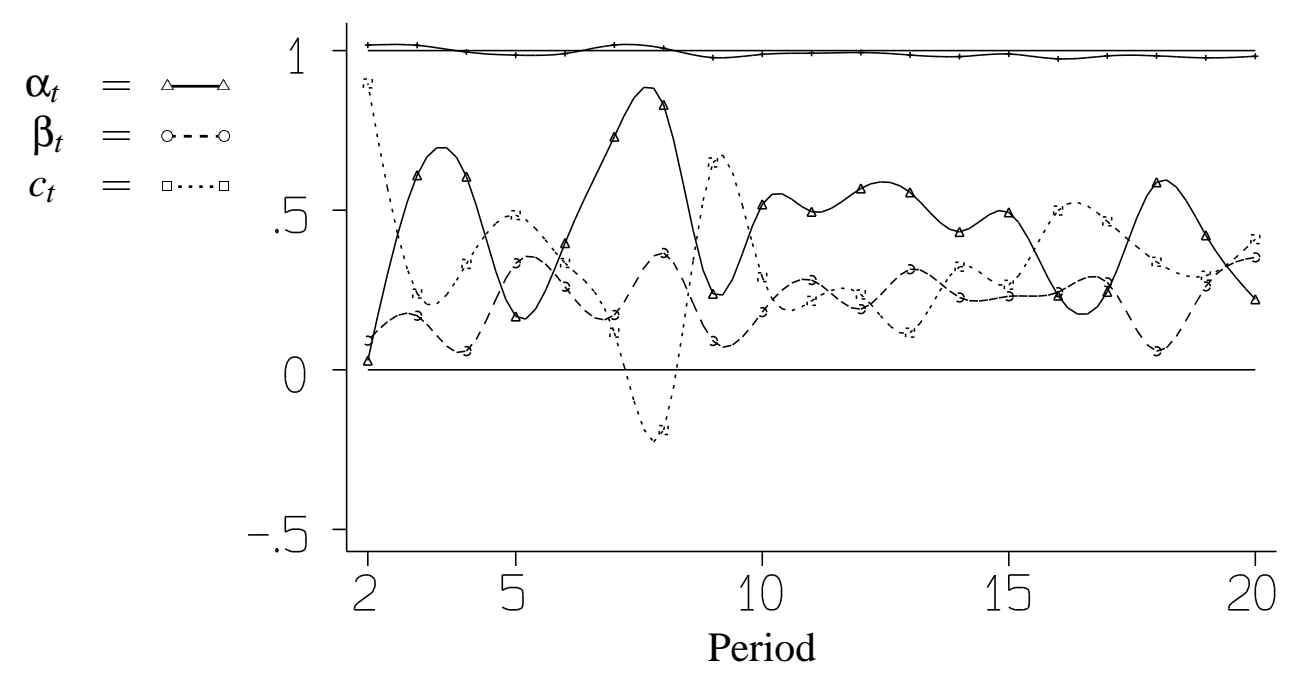

Figure 8: Adaptive learning parameters from eq. 16 over time 

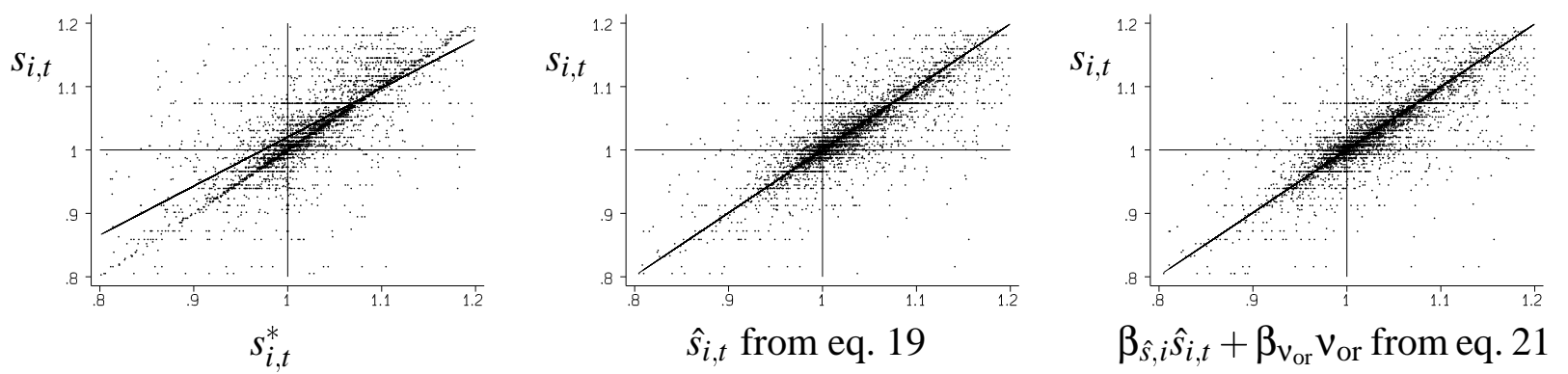

Actual saving can be explained rather well as a convex combination of optimal saving and past saving.

Figure 9: Actual saving versus optimal saving

\subsubsection{How forecasts are translated into saving decisions}

The important assumption of the theoretical model to which we now direct attention is that of certainty equivalent behaviour, namely, the hypothesis that individuals implement their optimal saving decisions given their forecasts, computing the former as if the latter were certain. Since with our experimental setup subjects first make forecasts, receiving from the computer a suggestion for an optimal saving decision, but then make their own choices, we can test this hypothesis. Such a direct test can for example be given by the regression of actual saving $s_{i, t}$ on optimal saving (given the individual forecast) $s_{i, t}^{*}$ as:

$$
s_{i, t}=\beta \cdot s_{i, t}^{*}
$$

which yields

\begin{tabular}{|c|c|c|c|c|c|}
\hline$\overline{s_{i, t}}$ & $\bar{\beta}$ & $\overline{\sigma_{\beta}}$ & $t$ & $\overline{P>|t|}$ & $95 \%$ conf. interval \\
\hline \multirow[t]{2}{*}{$s_{i, t}^{*}$} & 1.015071 & .0012107 & 838.384 & 0.000 & $1.012698 \quad 1.017445$ \\
\hline & & & $F_{\beta=1}^{1,7328}=154.95$ & $P_{>F}=0.0000$ & \\
\hline
\end{tabular}

Under certainty equivalent, $\beta$ should of course be 1 . While the regression shows that the optimal saving recommendations are clearly important for the individual actual decisions, the hypothesis of certainty equivalent that only recommendations matter (i.e. $\beta=1$ ) is clearly rejected (see also graph top left of figure 9 ).

We now present the result of a search for a specification which can best represent actual saving. We start running for each player $i$ a regression that explains actual saving $s_{i, t}$ as a linear function of the saving recommendation $s_{i, t}^{*}$ for this player at the given period and of past saving $s_{t-1} \ldots s_{t-n}$ of the last $n$ periods. We ran regressions for different values of $n$. For $n=4$, we obtained:

$$
s_{i, t}=\beta_{s^{*}, i} s_{i, t}^{*}+\beta_{s 1, i} s_{t-1}+\beta_{s 2, i} s_{t-2}+\beta_{s 3, i} s_{t-3}+\beta_{s 4, i} s_{t-4}
$$

Figure 10 shows the cumulative distribution of $\beta_{s^{*}, i}$, i.e. of the weight that a player attaches to the level of optimal saving, given his or her own expectations. We see that most players put weight less than one on their own optimal saving.

for second order rules, though in our case the results do not improve much on the first order. 


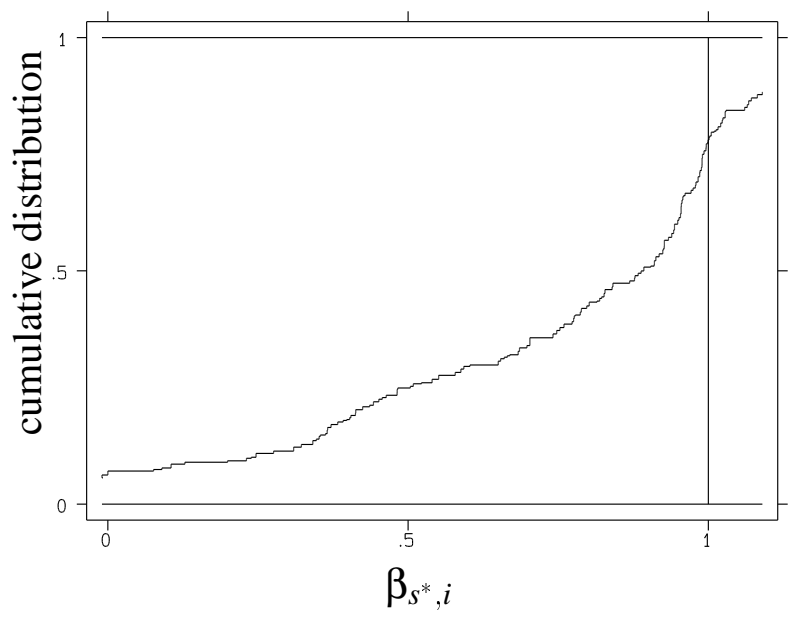

The figure shows the cumulative distribution of the weight on optimal saving $\beta_{s^{*}, i}$ given own expectation.

Figure 10: Weight on optimal saving

\begin{tabular}{|c|c|c|c|c|c|}
\hline$s_{i, t}$ & $\bar{\beta}$ & $\sigma_{\beta}$ & $F$ & $P>|F|$ & $95 \%$ conf. interval \\
\hline \multicolumn{3}{|c|}{ All Places } & & & $\overline{66155 \text { observations }}$ \\
\hline$\hat{s}_{i, t}$ & 1.010477 & .0009998 & $F_{\beta=1}^{1,6154}=109.80$ & 0.0000 & $1.008517 \quad 1.012437$ \\
\hline
\end{tabular}

Table 3: Estimation of equation 20

They seem, however, to compensate quite efficiently for a smaller weight they put on $\beta_{s^{*}, i}$. Figure 11 shows for each player the factor for the saving recommendation $\beta_{s^{*}, i}$ as well as the weight of the past saving, summarised as $\beta_{s 1}+\beta_{s 2}+\beta_{s 3}+\beta_{s 4}$. The observations in the figure can easily be approximated with a straight line: thus, players almost construct a convex combination $\beta_{s^{*}}+\sum_{\tau} \beta_{s \tau}=1$, of past saving and their saving recommendations to decide what amount they should really save.

Claiming that weights really add up to one, i.e. $\forall_{i}: \beta_{s^{*}, i}+\sum_{\tau} \beta_{s \tau, i}=1$, we can construct saving predictions $\hat{s}_{i, t}$ as follows:

$$
\hat{s}_{i, t}=\left(1-\beta_{s 1, i}-\beta_{s 2, i}-\beta_{s 3, i}-\beta_{s 4, i}\right) s_{i, t}^{*}+\beta_{s 1, i} s_{t-1}+\beta_{s 2, i} s_{t-2}+\beta_{s 3, i} s_{t-3}+\beta_{s 4, i} s_{t-4}
$$

To check the extent to which predicted saving $\hat{s}_{i, t}$ explains actual saving $s_{i, t}$, we ran a simple regression:

$$
s_{i, t}=\beta_{\hat{s}} \hat{s}_{i, t}
$$

Results of the estimation are displayed in table 3 We see that the model explains the individual saving decision nicely (see also the graph in the middle of figure 9). There is, however, still a small but highly significant amount of over-saving left to explain.

Precautionary saving might be one reason for over-saving. Precautionary saving should be higher when the subject is more uncertain about the future, which might be 


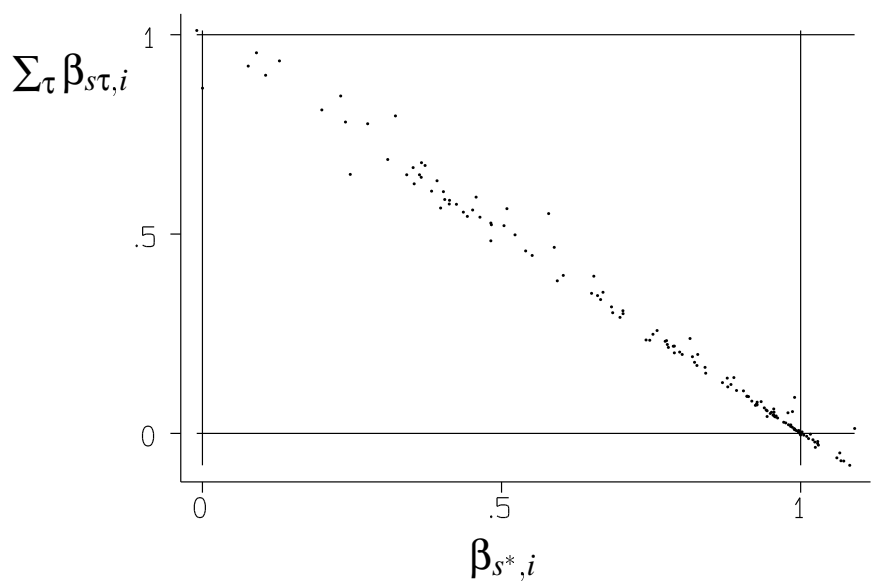

The figure shows the sum of weights that agents attribute to past saving $\beta_{s 1}+\beta_{s 2}+\beta_{s 3}+\beta_{s 4}$ over the weight agents attribute to optimal saving.

Figure 11: The impact of past saving versus optimal saving

reflected in the volatility of the subject's forecast 13 .

We take the measure $\dot{v}_{\text {or }}=v_{\text {or }}-\bar{v}_{\text {or }}$ as a proxy for motives to over-save. As defined above $v_{\text {or }}=\ln \ln ^{2}\left(\pi_{t} / \pi_{t-1}\right)$. This makes interpretation of the coefficients in the following equation easier:

$$
s_{i, t}=\beta_{\hat{s}, i} \hat{s}_{i, t}+\beta_{\dot{v}_{\text {or }}} \dot{v}_{\text {or }}
$$

The averages are displayed in table 4, the relation between the predicted and the actual values is displayed in the right graph of figure 9 The factor $\beta_{\hat{s}, i}$ is no longer significantly different from 1 . Thus, volatility is a possible explanation of over-saving 14

\footnotetext{
${ }^{13}$ The effect on saving of uncertainty may in general be ambiguous. In, however, the present experiment an increase in the uncertainty about the rate of inflation (interpreted in the sense of a Rothschild and Stiglitz (1970) mean preserving spread) implies higher savings. To see this, let the individual's beliefs about the value of the price ratio $\pi$ be summarised by a non-degenerate cumulative distribution function $F(\cdot)$ over a closed interval $[\underline{\pi}, \bar{\pi}]$, with $\underline{\pi}>0$. The subject's problem is then to choose $S$ so as to

$$
\max \int_{\underline{\pi}}^{\bar{\pi}}\left(\omega_{1}-S\right)\left(\omega_{2}+\frac{S}{\pi}\right) d F(\pi)
$$

The first order condition for an interior solution yields:

$$
S=\frac{1}{2}\left(\omega_{1}-\frac{1}{E[1 / \pi]} \omega_{2}\right)
$$

where the expectation is taken with respect to $F$. Clearly, if the subject has a point expectation about $\pi$, there is no uncertainty as assumed by the theoretical model of section 2 and the optimal decision is given by equation 5 If, however, $F(\cdot)$ is non-degenerate, then, given that for a generic random variable $X$ it is $E[1 / X] \approx 1 / E[X]+\sigma_{X}^{2} /(E[X])^{3}$ (where $\sigma_{X}^{2}$ is the variance of $X$ ), it straightforwardly follows that the greater the uncertainty about the rate of inflation, the higher must be the saving in the experiment.

${ }^{14}$ We have estimated the two regimes separately and found that the resulting coefficients are not significantly different.
} 


\begin{tabular}{|c|crrrrr|}
\hline$s_{i, t}=\beta_{\hat{s}, i} \hat{s}_{i, t}+\beta_{\dot{v}_{\text {or }}} \dot{v}_{\text {or }}$ & $\beta$ & $\sigma_{\beta}$ & \multicolumn{1}{c|}{$t$} & $P>|t|$ & $95 \%$ conf. interval \\
\hline$\beta_{\hat{s}, i}$ & 1.000082 & .0009147 & 1093.322 & 0.000 & .9982887 & 1.001875 \\
$\beta_{\dot{v}_{\text {or }}}$ & .0004563 & .0003373 & 1.353 & 0.176 & -.0002049 & .0011175 \\
\hline
\end{tabular}

Table 4: Volatility explains part of the over-saving

\section{Theoretical and policy implications of over-saving}

Having presented the results mechanically, we now discuss in more detail how they can be interpreted and what can be learned from them. Summarising the macro evidence, while we find some support for Friedman's conjecture that the money growth rule generates less inflation volatility than the constant real deficit rule, we also find an unexpected trade-off between the two rules: the money growth rule produces more average inflation and less average saving than the real deficit rule.

There are two possible explanations of this latter effect at micro level. One is that the monetary regimes affect the average saving level which in turn would be responsible for the different level of inflation. Alternatively, perhaps the average level of saving is not affected by the monetary regimes, while the different monetary regimes yield different inflation levels given the same behaviour. We find little support for the first hypothesis: while we observe over-saving under both regimes (and the saving regressions confirm that there is no systematic difference between the two in the amount of over-saving), we have inflation below the equilibrium level only under the constant real deficit rule, but not under the constant money growth rule.

This result gives independent support for the second hypothesis. Clearly, constant over-saving leads to inflation rates lower than the equilibrium values under the constant real deficit regime, but will not affect inflation at all under the money growth rule: rewriting equations 6 and 7 of section 2 and assuming constant saving behaviour $s_{t}=s_{t-1}=s$ yields

$$
\pi=\frac{\mu s}{s-d}
$$

With the money growth regime $(d=0)$, the inflation rate is $\mu$ when the saving level is constant over time. With the constant real deficit regime $(d>0)$ the inflation rate decreases in $s$.

Thus, persistent over-saving, which our regressions have shown to be mainly precautionary, might be the reason for the different inflation levels observed under the two regimes in the experiments. Even more importantly, we will now show that also the difference in the inflation volatility of the two regimes is perhaps due to the same phenomenon of over-saving.

To this end, let us consider a linear model of over-saving and change equation 4 as follows:

$$
s_{t}=\gamma+2 \zeta \frac{1}{2}\left(\omega^{1}-\frac{p_{t+1}}{p_{t}} \omega^{2}\right)
$$

A rational agent, in a world of no-uncertainty, would (as in equation 4) choose $\gamma=0$ and 
$\zeta=1 / 2$; a purely over-saving agent might choose $\gamma>0$ or $\zeta>1 / 2$; an agent who further saves a convex combination of past saving and best reply might choose $\gamma>0$ and $\zeta<1 / 2$.

The equilibrium map (see equation 8 ) is now:

$$
-d+\gamma+\zeta \omega_{1}-\zeta \pi_{t+1}^{e} \omega_{2}-\frac{\mu\left(\gamma+\zeta \omega_{1}-\zeta \pi_{t}^{e} \omega_{2}\right)}{\pi_{t}}=0
$$

Assuming first-order adaptive learning, and following the same procedure of integration and linearisation applied through equations 13 to 14 of section 2, we can study the local stability properties of the two monetary rules in the experiment. As in section 2 , with complex eigenvalues, stability depends on the contraction factor:

$$
\frac{\widehat{\pi} \alpha \omega_{2}}{\frac{\gamma}{\zeta}+\omega_{1}-\widehat{\pi} \omega_{2}}
$$

where $\widehat{\pi}$ is the inflation rate observed in the experiment.

The greater this expression, the more likely the system is to be stable. Since this expression does not depend on the parameters of the two monetary rules one might argue that the rules should not lead to different volatility of inflation.

With over-saving, however, this result is no longer correct. Since, as we have seen in particular in equation 22, over-saving leads to lower inflation levels under the real deficit regime, but not under the money growth regime, the different levels of inflation under the two regimes can also explain their different volatility.

We would also emphasise that this trade-off between the two monetary rules we find in the experiment may not be trivial from a policy perspective. The two regimes, being designed to be theoretically equivalent in terms of government revenues in a world with no-uncertainty and rational agents, are still equivalent in the experiment, despite the deviations from the theoretical predictions we have observed. With the constant real deficit regime the inflation level is lower than equilibrium, but this cannot influence the revenues, since they are by definition constant under this regime. Conversely, the experimental properties of the constant money growth regime are 'similar' to the equilibrium properties: the inflation level is on average very close to the equilibrium, so that we should expect the government revenues to be close to the equilibrium as well.

This intuition is confirmed by the cumulative distributions of the government revenues under the two regimes (figure 12). We see that both regimes yield, on the average, similar government revenues, and can thus be considered equivalent not only in equilibrium, but also in the experiment.

We finally note that while on the one hand the evidence we have reported might be considered to support Friedman's conjecture on the lower volatility of inflation under the money growth rule, on the other hand it contrasts with a second conjecture also advanced by Friedman in his Nobel Lecture (Friedman 1977). There he suggested that a positive relationship exists between the level of inflation and the volatility of future inflation rates, the so-called inflation-uncertainty hypothesis. This conjecture has spawned a very general, but not conclusive empirical literature. For example, as noted by Evans (1991): "Although economists have long suspected that inflation rates and inflation uncertainty are tightly linked, the statistical evidence is surprisingly ambiguous". Our results may 


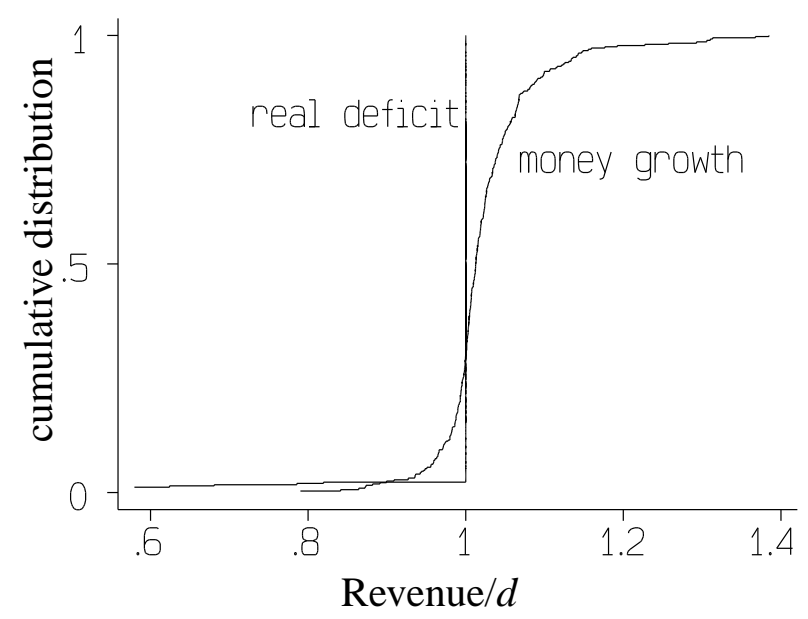

Revenues are normalised to 1 in the low ISS. The vertical line at 1 shows the constant real deficit regime, the curved line shows the money growth regime.

Figure 12: Cumulative distribution of government revenues

help to explain why. Friedman advanced his second conjecture in a context of uncertainty of the monetary regime, rather than in a context of comparison between regimes: "A burst of inflation produces strong pressure to counter it. Policy goes from one direction to the other, encouraging wide variation in the actual and anticipated rate of inflation" (Friedman, 1977, pp. 466). Our evidence and the analysis conducted above, however, show that even when the regimes are certain there may still be an important, though more subtle, source of endogenous uncertainty, affecting agents' behaviours and the actual inflation rates, through the stability properties of the adaptive dynamics of the different regimes.

\section{Concluding remarks on the literature of adaptive learning}

The last observation of the previous section brings us to consider an ultimate, more general question underlying our experimental investigation and concerning the extent to which, as in some current research (see the comprehensive survey in Evans and Honkapohja (1999)), different monetary policies can be studied and possibly ranked according to the stability properties of their adaptive dynamics.

The answer provided by our evidence is not simple. On the one hand, from an ex ante position, considering that the theoretical stability properties of the two monetary rules we study imply equivalence of the two regimes, we should reject stability analysis because inconsistent with our observation. From an ex post position, however, after rejecting the equivalence hypothesis on empirical grounds, we have used stability analysis - in the light of the observed deviations from optimal saving decisions - to explain the different inflationary impacts of the rules.

Should the ex ante- or the ex post-perspective be preferred? The answer depends on 
the aims of the analysis. If the purpose of the analysis is to understand and to describe what one observes in the data, our experiments clearly confirm that the theory of adaptive learning may be quite fruitful. If instead one wishes to derive policy recommendations simply by the theoretical stability properties of alternative policy options, much more caution should be used. Attention must in particular be paid to the possible effects of the large number of issues which, unavoidably, a theoretical model must abstract from; but which, if taken into account, may affect the conclusion of stability analysis substantially.

This seems an obvious consideration, valid for any of theoretically-based policy recommendation. But in the present case, it assumes a special importance. We in particular emphasise that the question we are addressing is not the reliability of the theory of adaptive learning in its final implications for equilibrium selection; but the extent to which adaptive learning can also be useful in an ex ante perspective, to anticipate fully the dynamic transitional aspects out of an equilibrium. It is this much more subtle issue, which is causing much debate among macroeconomists (e.g. Sargent (1993), Honkapohja (Honkapohja 1995), Farmer (1996)).

The problem seems to be that "the environments into which we have cast our adaptive agents seem much more stable and hospitable than the real life situations for which we would want transition dynamics" (Sargent (1993, p. 169)). An important specific difficulty seems to be that the environments in which adaptive agents are normally embedded typically refer to general equilibrium economies where there is no uncertainty. While this assumption could perhaps be justified in models of rational expectations (since, by definition, in such models the economy is always in equilibrium) a characteristic of the models of adaptive learning is precisely that the actual law of motion of the forecasted variables differ, during the transitional process, from the perceived law of motion, so giving rise to an obvious source of endogenous uncertainty. In this respect, we would conclude by noting that among the different factors one may have to consider in future research to increase the robustness of monetary policy recommendations based on stability analysis, special efforts should be made to check how robust the recommendations are, in view of the effect that endogenous inflation uncertainty may have on agents' behaviours.

\section{References}

Bernasconi, M., and O. Kirchkamp, 1998, Why monetary policy matters - An experimental study of saving, inflation and monetary policies in an overlapping generations model, Discussion Paper 98-47, SFB 504, Universität Mannheim, http://www.kirchkamp.de/

Bruno, M., and S. Fisher, 1990, Seigniorage, Operating Rules and the High Inflation trap, Quarterly Journal of Economics, 105, 353-374.

Cagan, P., 1956, The Monetary Dynamics of Hyperinflation, in Studies in the Quantity Theory of Money, ed. by M. Friedman. University of Chicago Press.

Evans, G. W., and S. Honkapohja, 1999, Learning dynamics, in Handbook of Macroeconomics, ed. by J. Taylor, and M. Woodford. Elsevier, Amsterdam, forthcoming. 
Evans, G. W., S. Honkapohja, and R. Marimon, 1996, Convergence in Monetary Models with Heterogeneous Learning Rules, Discussion Paper 1310, Centre for Economic Policy Research.

Evans, M., 1991, Discovering the link between inflation rates and inflation uncertainty, Journal of Money, Credit and Banking, 23, 169-184.

Farmer, R. E., 1996, Macroeconomics and learning, mimeo.

Friedman, M., 1948, Monetary and Fiscal Framework for Economic Stability, The American Economic Review, 38, 245-264.

, 1957, The Theory of the Consumption Function. Princeton University Press, Princeton, New Jersey.

— , 1960, A Program for Monetary Stability. Fordham University Press, New York.

- 1977, Nobel Lecture: Inflation and Unemployment, Journal of Political Economy, 85, 451-472.

Honkapohja, S., 1995, Bounded rationality in Macroeconomics. A review essay, Journal of Monetary Economics, 35, 509-518.

Lim, S., E. C. Prescott, and S. Sunder, 1994, Stationary Solution to the Overlapping Generations Model of Fiat Money: Experimental Evidence, Empirical Economics, 19, 1005-1014.

Marcet, A., and T. J. Sargent, 1989, Convergence of Least Squares Learning Mechanisms in Self-Referential Linear Stochastic Models, Journal of Economic Theory, 48, 337368.

Marimon, R., 1997, Learning from learning in economics, in Advances in economics and econometrics: Theory and applications: Symposia paper of the 7th World Congress of the Econometric Society, ed. by D. M. Kreps, and K. F. Wallis, vol. 26 of Econometric Society Monographs, p. 332, Cambridge. Cambridge University Press.

Marimon, R., S. E. Spear, and S. Sunder, 1993, Expectationally-Driven Market Volatility: An Experimental Study, Journal of Economic Theory, 61(1), 74-103.

Marimon, R., and S. Sunder, 1993, Indeterminacy of Equilibria in a Hyperinflationary World: Experimental Evidence, Econometrica, 61, 1073-1107.

, 1994, Expectations and learning under alternative monetary regimes: an experimental approach, Economic Theory, 4, 131-162.

-1995 , Does a constant money growth rule help stabilize inflation?: Experimental evidence, Carnegie-Rochester Conference Series on Public Policy, 43, 111-156.

Romer, P. M., 1995, Advanced macroeconomics. McGraw, New York. 
Rothschild, M., and J. Stiglitz, 1970, Increasing risk: 1. A definition, Journal of Economic Theory, 2, 225-243.

Sargent, T. J., 1993, Bounded Rationality in Macroeconomics. Clarendon-Oxford University Press, Oxford.

Sargent, T. J., and N. Wallace, 1987, Inflation and the Government Budget Constraint, in Economic Policy in Theory and Practice, ed. by A. Razin, and E. Sadka. Macmillan, New York.

Sugden, R., 1995, A Theory of Focal Points, Economic Journal, 105, 533-550. 


\section{A List of experiments}

\begin{tabular}{|c|c|c|c|c|c|c|}
\hline \multicolumn{7}{|c|}{ Experiments run in Florence 5/97 } \\
$n$ & Players & Session & Periods & Label & $d=\frac{167}{160}$ & $\omega_{1}$ \\
\hline 1 & 12 & 1 & 13 & EC & 0 & 600 \\
1 & 12 & 2 & 11 & Euro-Bank & 1 & 600 \\
1 & 12 & 3 & 7 & EC & 0 & 600 \\
\hline 2 & 6 & 1 & 14 & EC & 0 & 480 \\
2 & 6 & 2 & 12 & Euro-Bank & 1 & 480 \\
\hline \hline
\end{tabular}

\begin{tabular}{|c|c|c|c|c|c|c|}
\hline \hline \multicolumn{7}{|c|}{ Experiments run in Mannheim 12/97 } \\
$n$ & Players & Session & Periods & Label & $d=\frac{167}{160}$ & $\omega_{1}$ \\
\hline 3 & 17 & 1 & 21 & - & 0 & 480 \\
3 & 17 & 2 & 12 & - & 1 & 480 \\
3 & 17 & 3 & 17 & - & 0 & 480 \\
3 & 17 & 4 & 5 & - & 1 & 480 \\
\hline 4 & 13 & 1 & 15 & BuBa & 1 & 480 \\
4 & 13 & 2 & 17 & EC & 0 & 480 \\
4 & 13 & 3 & 16 & BuBa & 1 & 480 \\
4 & 13 & 4 & 15 & EC & 1 & 480 \\
\hline 5 & 16 & 1 & 24 & BuBa & 0 & 600 \\
5 & 16 & 2 & 28 & BuBa & 0 & 600 \\
5 & 16 & 3 & 59 & EC & 0 & 600 \\
\hline 6 & 15 & 1 & 19 & EC & 1 & 900 \\
6 & 15 & 2 & 14 & BuBa & 0 & 900 \\
6 & 15 & 3 & 19 & EC & 1 & 900 \\
\hline 7 & 20 & 1 & 23 & EC & 1 & 750 \\
7 & 20 & 2 & 43 & BuBa & 0 & 750 \\
7 & 20 & 3 & 18 & EC & 1 & 750 \\
\hline 8 & 19 & 1 & 19 & - & 0 & 600 \\
8 & 19 & 2 & 55 & - & 1 & 600 \\
\hline \hline
\end{tabular}

\begin{tabular}{|c|c|c|c|c|c|c|}
\hline \hline \multicolumn{7}{|c|}{ Experiments run in Pavia 4/98 } \\
$n$ & Players & Session & Periods & Label & $d=\frac{167}{160}$ & $\omega_{1}$ \\
\hline 9 & 14 & 1 & 24 & BuBa & 1 & 480 \\
9 & 14 & 2 & 15 & BuBa & 0 & 480 \\
9 & 14 & 3 & 10 & BuBa & 1 & 480 \\
9 & 14 & 4 & 15 & BuBa & 0 & 480 \\
\hline 10 & 14 & 1 & 7 & EC & 1 & 900 \\
10 & 14 & 2 & 19 & EC & 1 & 900 \\
10 & 14 & 3 & 9 & EC & 1 & 900 \\
\hline 11 & 13 & 1 & 21 & EC & 1 & 540 \\
11 & 13 & 2 & 21 & BuBa & 0 & 540 \\
11 & 13 & 3 & 8 & EC & 1 & 540 \\
\hline 12 & 14 & 1 & 21 & EC & 0 & 750 \\
12 & 14 & 2 & 8 & EC & 0 & 750 \\
12 & 14 & 3 & 7 & EC & 0 & 750 \\
12 & 14 & 4 & 21 & BuBa & 1 & 750 \\
\hline 13 & 14 & 1 & 24 & BuBa & 1 & 750 \\
13 & 14 & 2 & 10 & BuBa & 1 & 750 \\
13 & 14 & 3 & 22 & EC & 0 & 750 \\
\hline
\end{tabular}

